\title{
On coalescent angiogenesis and the remarkable flexibility of blood vessels
}

\author{
Francesco Pezzella ${ }^{1} \cdot$ Robert S. Kerbel ${ }^{2}$
}

Published online: 7 January 2022

(c) Crown 2021

There is no better place to appreciate the complexity of the human vascular system than the XVII century Chapel Sansevero in the heart of Naples. Such is the power of these "Anatomical Machines" (Fig. 1) that, according to the Italian philosopher Benedetto Croce, the legend says that Raimondo di Sangro, Prince of Sansevero and a XVIII century alchemist, "had two servants, a man and a woman, killed and embalmed in such a way that their bodies would display all their viscera, arteries and veins". An even darker story claims that the prince would have injected the servants, still alive, with a mysterious fluid that would have transformed the blood into solid metal. In reality, while the two skeletons supporting the vascular system model are real, the vessels are not and are modelled using metal wire twisted with fibres and covered with coloured wax [1]. Despite being a "simple model", these machines highlight the incredible complexity of the vascular system and suggesting aspects of its formation and how it keeps adapting to the body, which must be incredibly highly complex.

Several types of events must happen to build and maintain a vascular system: actual production of new vessels and remodelling of pre-existing ones are the two main ones and, as we will see, the distinction between the two is blurred and providing a precise nomenclature for all the different aspects can be difficult. Vasculogenesis and angiogenesis, defined as sprouting angiogenesis, are the two processes which lead to formation of entirely new vessels. This is in contrast to non-sprouting angiogenesis where pre-existing vessels exist and can split through intussusceptive angiogenesis, resulting

Francesco Pezzella

francesco.pezzella@ndcls.ox.ac.uk

1 Nuffield Division of Laboratory Science, Radcliffe Department of Medicine, John Radcliffe Hospital, University of Oxford, Oxford OX3 9DU, UK

2 Biological Sciences Platform, Department of Medical Biophysics, Sunnybrook Research Institute, University of Toronto, Toronto, Canada in each of the two resulting vessels being made up by some pre-existing structure and some newly formed one.

Vasculogenesis is somehow the easiest to define and refers to the maturation of stem cells from mesoderm into angioblasts and then their differentiation into blood vessels including the endothelial component [2]. It is predominant during embryonic development and leads to the appearance of vessels where before there were none.

In contrast, with angiogenesis, things are not always that clear. Initially defined as "the sprouting of vessels from preexisting vessels" the definition has been made broader to include "non-sprouting angiogenesis" [3]. Drake and Little instead are more specific and state that " .... the expansion of the vasculature by angiogenesis is dependent on the generation of new endothelial cells from pre-existing vascular beds"[4]. Broader definitions have followed with angiogenesis described e.g., as "...the generation and expansion of blood vessels from a pre-existing vascular network under endogenous or exogenous stimuli" [5]. Which adds to the less well-defined concept of "expansion" to accommodate "non-sprouting angiogenesis". Intussusceptive or splitting microvascular growth and glomeruloid microvascular proliferation are now defined as angiogenesis, but of the nonsprouting type [6].

Vascular remodelling refers to two main types: remodelling of the actual structure of a vessel, e.g., rearrangement of the smooth muscles cells in an artery[7], or remodelling of the pattern of a network of vessels, and it is the latter to be discussed in this editorial. This type of remodelling of a vascular network is based on generation of new vessels by angiogenesis alongside the regression and eventual disappearance of vessels no longer useful [8], or by fusion of smaller vessels to larger ones and the splitting of large vessels into smaller ones. In the embryo, remodelling of the vessels includes extensive cell death, triggered by low blood flow and lack of nutrients or other environmental factors.

Where does the biological process called "Vascular fusion" [4] or "Hormetic fusion" [9] or, as reported in this 


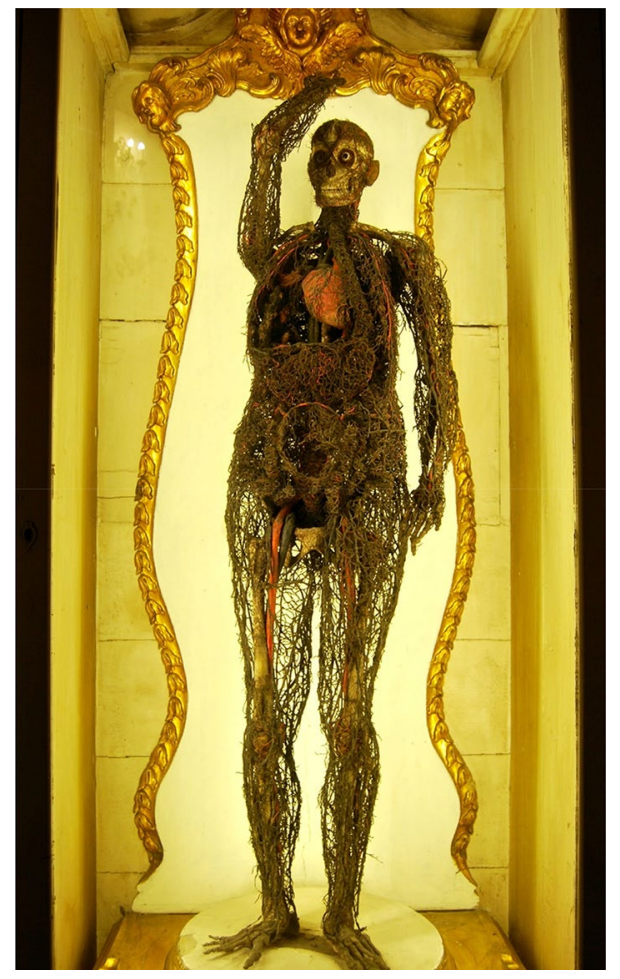

Fig. 1 One of the two "anatomical machines", Sansevero Chapel

issue of Angiogenesis by Nitzsche et al. [10], "Coalescent angiogenesis" stand in the overall context of blood vessel formation? It is a process whose goal is to quickly, within a time frame of hours [11], provide a larger vessel by fusing two smaller one along the longitudinal axis.

The early form of "fusion" is among the initial vascular vesicles in the embryo leading to the formation of a proper vascular channel [12]. The vascular fusion we are discussing here is the one occurring between established vascular channels [13]. It was initially described to happen during the formation of the dorsal aorta. The dorsal aortae are formed by vasculogenesis type $\mathrm{I}$, in which the angioblasts arise in place at the site of vessel formation leading to formation of a meshwork of small vessels [14]. The fusion process originates in such a meshwork of small vessels and culminates with the two original symmetric aortae fusing below T4 [15-17].

The description and investigation of this aspect of vascular biology has, however, remained in the domain of embryologists and has been completely overlooked by the community of cancer researchers interested in tumour vascularization and it is not even mentioned in the classic textbook on angiogenesis by Figg and Folkman [18], thus having both the authors and reviewers of the manuscript published in this issue of angiogenesis [10] caught off guard!

Most of the studies published so far focus on how a uniform mesh of small capillaries is remodelled into a branching tree of larger vessels, becoming progressively smaller, a process in which the total number of vessels is reduced, but their diameters are increased. As far as how a vessel can enlarge, there are actually three different mechanisms so far described: one is fusion, while the other two are migration and proliferation [11]. Briefly, in migration, the endothelial cells migrate from the vascular network branches with weakest flow to the branches with highest flow, while in proliferation, or arteriogenesis, defined as the development of collateral arteries from pre-existing arteriolar connections requiring the proliferation of endothelial cells and smooth muscle cells [19], endothelial proliferation is observed in vascular branches with increased blood flow. Fusion, or coalescence, is the latest mechanism proposed and is a very common one during embryogenesis [11].

Thoma [20] for the first time presented evidence that a combination of velocity of flow and/or pressure and growth of surrounding tissue and resulting wall stress are factors initiating vascular sprouting and growth in chick embryos thanks to activation of what we now know to be mechanoreceptors. Also, for vascular fusion, this is the case. The upstream trigger is shear stress, i.e., " ...the force exerted by flow and expressed either in $\mathrm{N}($ Newton$) / \mathrm{m}^{2}$ (i.e., Pascals) or dyne/cm2" [11]. It is such increases in shear stress which trigger, through mechano receptors, the activation of the molecular events leading to fusion [17, 21, 22].

In another study instead, it was reported that increased shear stress was associated with less fusion. However, the authors used a model in which they modified shear stress by viscosity levels and describe that the higher shear stress (i.e., viscosity) is associated with less vascular fusion, but only in the arterial and not in the venous plexus [21].

Little is known at the moment of which molecular events are triggered by alteration in shear stress and how these induce fusion. In mouse embryos vascular fusion is associated with lower shear stress, as defined by viscosity rather than flux, and can also be induced by Notch inhibition [21, 23]. Notch inhibition is followed by increased levels of phospho-Vascular Endothelial Cadherin (VEC). Blocking VEC phosphorylation, by inhibition of the tyrosine-protein kinases Src, stops the vascular fusion process[23]. Instead, in the chicken embryo model, fusion has been found associated with increased levels of VEGF. VEGF induces transcription of Delta-like ligand 4 which, once on the cell membrane, will link to its receptor Notch. How these first steps eventually result in vascular fusion is still unknown [21].

Does vessel fusion/coalescence have any role beyond embryogenesis? We do not know as, so far, it has not been described in any other setting. One added difficulty is that, in a still image, two vessels undergoing fusion would be, as far as morphology is concerned, not distinguishable from intussusceptive angiogenesis [11]. Only when we will have biomarker distinguishing between the two processes, will we 
be able to differentiate between these phenomena in tissues. Until then we will have to rely on dynamic observations of models.

\section{References}

1. Dacome L, Peters R (2007) Fabricating the body: the anatomical machines of the Prince of Sansevero. In: Green V, Griffin P, Del $\mathrm{Re} C$ (eds) Object specialty group postprints, vol 14. The American Institute for Conservation of Historic and Artistic Works, Washington DC, USA, pp. 161-167

2. Risau W, Flamme I (1995) Vasculogenesis. Annu Rev Cell Dev Biol 11:73-91. https://doi.org/10.1146/annurev.cb.11.110195. 000445

3. Folkman J (1995) Seminars in medicine of the Beth Israel Hospital, Boston. Clinical applications of research on angiogenesis. N Engl J Med 333(26):1757-1763. https://doi.org/10.1056/NEJM1 99512283332608

4. Drake CJ, Little CD (1995) Exogenous vascular endothelial growth factor induces malformed and hyperfused vessels during embryonic neovascularization. Proc Natl Acad Sci U S A 92(17):7657-7661. https://doi.org/10.1073/pnas.92.17.7657

5. Kornowski R, Epstein SE, Leon MB (1999) Handbook of myocardial revascularization and angiogenesis. Martin Dunitz Ltd, London

6. Dome B, Hendrix MJ, Paku S, Tovari J, Timar J (2007) Alternative vascularization mechanisms in cancer: pathology and therapeutic implications. Am J Pathol 170(1):1-15. https://doi.org/10. 2353/ajpath.2007.060302

7. McGrath JC, Deighan C, Briones AM, Shafaroudi MM, McBride M, Adler J, Arribas SM, Vila E, Daly CJ (2005) New aspects of vascular remodelling: the involvement of all vascular cell types. Exp Physiol 90(4):469-475. https://doi.org/10.1113/expphysiol. 2005.030130

8. Owen MR, Alarcon T, Maini PK, Byrne HM (2009) Angiogenesis and vascular remodelling in normal and cancerous tissues. J Math Biol 58(4-5):689-721. https://doi.org/10.1007/ s00285-008-0213-z

9. Fosslien E (2013) Theoretical and experimental models of hormetic fusion tubulogenesis. Dose Response 11(2):178-190. https://doi.org/10.2203/dose-response.12-004.Fosslien

10. Nitzsche B et al (2021) Coalescent angiogenesis-evidence for a novel concept of vascular network maturation. https://doi.org/10. 1007/s10456-021-09824-3

11. Gifre-Renom L, Jones EAV (2021) Vessel enlargement in development and pathophysiology. Front Physiol 12:639645. https:// doi.org/10.3389/fphys.2021.639645
12. Noden DM (1989) Embryonic origins and assembly of blood vessels. Am Rev Respir Dis 140(4):1097-1103. https://doi.org/10. 1164/ajrccm/140.4.1097

13. Drake CJ, Jacobson AG (1988) A survey by scanning electron microscopy of the extracellular matrix and endothelial components of the primordial chick heart. Anat Rec 222(4):391-400. https://doi.org/10.1002/ar.1092220411

14. Poole TJ, Coffin JD (1991) Morphogenetic mechanisms in avian vascular development. In: Feinberg RN, Sherer GK, Auerbach R (eds) The development of the vascular system. Karger, Basel, pp 25-36

15. Effmann EL, Whitman SA, Smith BR (1986) Aortic arch development. Radiographics 6(6):1065-1089. https://doi.org/10.1148/ radiographics.6.6.3685519

16. Croce B (1923) Storie e leggende napoletane. 2nd edition. Giuseppe Laterza and Figli, Bari, Italy, pp 296-297

17. Sato Y, Poynter G, Huss D, Filla MB, Czirok A, Rongish BJ, Little CD, Fraser SE, Lansford R (2010) Dynamic analysis of vascular morphogenesis using transgenic quail embryos. PLoS ONE 5(9):e12674. https://doi.org/10.1371/journal.pone.0012674

18. Figg WD, Folkman J (2008) Angiogenesis. An integrative approach from science to medicine. Springer, New York, USA

19. Buschmann I, Schaper W (2000) The pathophysiology of the collateral circulation (arteriogenesis). J Pathol 190(3):338-342. https://doi.org/10.1002/(SICI)1096-9896(200002)190:3\%3c338: AID-PATH594\%3e3.0.CO;2-7

20. Thoma R (1893) Untersuchungen über die Histogenese and Histomechanic des Gefässystems. Enkeverlag, Stuttgart

21. Chouinard-Pelletier G, Jahnsen ED, Jones EA (2013) Increased shear stress inhibits angiogenesis in veins and not arteries during vascular development. Angiogenesis 16(1):71-83. https://doi.org/ 10.1007/s10456-012-9300-2

22. Udan RS, Vadakkan TJ, Dickinson ME (2013) Dynamic responses of endothelial cells to changes in blood flow during vascular remodeling of the mouse yolk sac. Development 140(19):40414050. https://doi.org/10.1242/dev.096255

23. Caolo V, Peacock HM, Kasaai B, Swennen G, Gordon E, Claesson-Welsh L, Post MJ, Verhamme P, Jones EAV (2018) Shear stress and VE-cadherin. Arterioscler Thromb Vasc Biol 38(9):2174-2183. https://doi.org/10.1161/ATVBAHA.118. 310823

Publisher's Note Springer Nature remains neutral with regard to jurisdictional claims in published maps and institutional affiliations. 